\title{
Strength and permeability of pervious composite prepared by using post-consumer plastic waste bottles
}

\author{
Pranshoo Solanki ${ }^{1, *}$, and Samikaran Bhattarai ${ }^{2}$ \\ ${ }^{1}$ Associate Professor of Construction Management, Department of Technology, Illinois State \\ University, Campus Box 5100, Normal, Illinois 61790, USA \\ ${ }^{2}$ Graduate Assistant, Department of Technology, Illinois State University, Campus Box 5100, \\ Normal, Illinois 61790, USA
}

\begin{abstract}
This study focused on developing and evaluating a novel form of pervious polyethylene terephthalate (PET) plastic composite. This novel composite, called as PPC, produced from plastic waste, soil and aggregates, will offer an effective technique for reducing storm water runoff and help divert a large amount of plastic from landfills and incinerators. PPC samples with different PET to soil/aggregate ratios were prepared and then tested for indirect tensile strength and permeability. Permeability was conducted in a unique manner by designing and fabricating a new testing equipment. Both indirect tensile strength and permeability were within the expected values found in the literature for porous pavements. Results showed that indirect tensile strength values increased with PET content. It was also found that using PET alone is not strong enough in binding aggregates and therefore, a soil/PET ratio of one was found optimum for providing maximum strength. Permeability values decreased with the decrease of A/P (aggregate/PET) ratio which in general indicates that lower PET and higher aggregate content is suitable for higher permeability. A soil/PET ratio of one was found to provide higher permeability but strength could compromise. Findings from this study indicated that developed PPC could be used for low-strength construction such as driveways, sidewalks and parking lots.
\end{abstract}

\section{Introduction}

According to Environmental Protection Agency [1], 32.5 million tons of plastic waste is generated annually in the United States (US), which is around $12.8 \%$ of entire municipal solid waste. However, only $9.2 \%$ of plastic (3.0 million tons) discarded annually is recycled [1]. Among the plastic materials, polyethylene terephthalate (PET) is a form of polyester and the most common consumer plastic. Beverages, food, and other consumer products are delivered in bottles or packages made from PET. In 2015, approximately 5,971 million pounds of PET bottles were sold into the marketplace in the US [2]. PET bottles have taken

\footnotetext{
* Corresponding author: psolanki@ilstu.edu
} 
the place of glass bottles as storing container of beverages due to its lightweight and easiness of handling and storage [3].

Generally, the empty PET bottles are discarded by the consumer after use and becomes PET waste. According to a recent study [4], 35 billion plastic bottles are thrown away annually in the US. The major problem that this level of waste production generates initially entail storage and elimination. In the case of PET, a thermoplastic, regeneration is feasible through recycling. Therefore, the post-consumer PET waste is sorted, crushed, pressed into bales and offered for sale to recycling companies [3]. Recycling companies further treat the post-consumer PET waste by shredding the material into small flakes which are used as raw material for a range of products. However, a vast amount of waste PET still remains un-used as it is one of the most abundant plastics in solid urban waste [3,5]. This results in the accumulation of plastic wastes and causes serious environmental problems due to littering and illegal landfilling or incineration.

One of the recycling methods of post-consumer PET waste is using it in concrete, one of the most widely used construction materials. Siddique et al. [6] and Sharma and Bansal [7] concluded that using plastics in conventional concrete has some advantages such as high toughness, good durability, longevity, lesser production cost, superior aesthetic appeal, and light weight. Utilizing PET waste in concrete not only provides an effective way of recycling PET [8-9], but also saving natural mineral resources and reducing the environmental pollution caused by cement production [10-12]. However, to the authors' knowledge no study attempted recycling of post-consumer PET waste bottles in sustainable pervious pavements.

Pervious pavements are unique and effective means to address important environmental issues and support sustainable growth. By capturing storm water and allowing it to seep into the ground, pervious pavement is capable of recharging groundwater, reducing storm water runoff and meeting US EPA's better management practice of storm water runoff [13]. Pervious concrete and porous asphalt are the most commonly used pervious pavement materials. Fig. 1 shows a specimen of pervious pavement material.

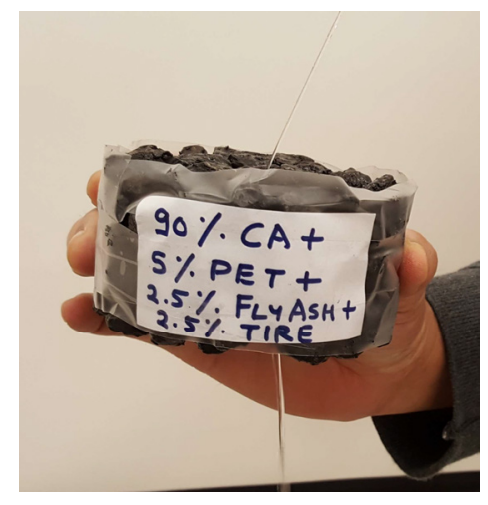

Fig. 1. Pervious pavement material showing flow of water

Both pavement types use the same materials as their conventional counterparts with the exception of including fines in the mix design and keeping the size distribution of coarse aggregates narrow for minimal particle packing (conventional concrete is mixture of Portland cement, coarse aggregates and fine aggregates). A pervious concrete mixture contains little or no fine aggregate, thus creating system of highly permeable and interconnected voids that drain quickly [14-15]. Utilization of post-consumer PET in pervious pavement will provide new market potential and greater likelihood for recycling by consuming the bulk of PET waste bottles and reduce the amount of waste entering landfills. Consequently, the aim of this study was to develop and evaluate novel form of pervious PET composite, called as PPC, by 
replacing $100 \%$ Portland cement in conventional pervious concrete with post-consumer PET waste bottles.

\section{Methodology and Experimental Design}

\subsection{Material Types and Sources}

A total of three types of materials namely, virgin aggregates, soil and PET bottles flakes were used in this study. Virgin aggregates were collected from Prairie Material, a local ready-mix concrete plant located in Normal, Illinois. Bulk aggregates were sieved in accordance with AASHTO M 43 test method which indicated maximum aggregate size of 1 inch. Soil was collected from Portico Homes LLC residential construction site located in Normal, Illinois. Air dried soil was tested for sieve analysis and Atterberg limits in accordance with ASTM D 422 and ASTM D 4318, respectively. Test results showed soil with percent passing \#200 of $15 \%$, liquid limit of $20 \%$ and plasticity index of $15 \%$. The post-consumer PET bottles were collected from Illinois State University (ISU) recycling facility and donated by students/faculty at ISU. These bottles were shredded into flakes by using Nelmor Grinder/Granulator Model No. G1012P1 at Midwest Fiber Recycling, Normal, IL. Fig. 2 shows photographic view of different materials used in this study.

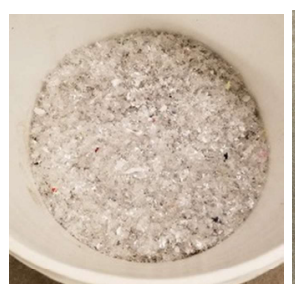

(a)

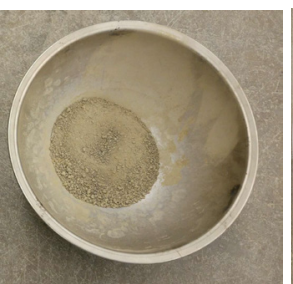

(b)

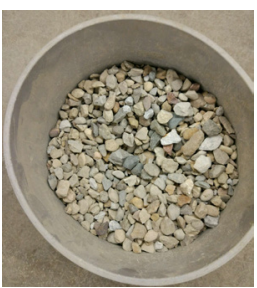

(c)

Fig. 2. Photographic view of (a) shredded PET bottle flakes, (b) soil, and (c) coarse aggregates

\subsection{Sample Preparation}

A total of five PPC mixtures were prepared in this study. A summary of different composite mixtures is presented in Table 1. All PPC mixtures were prepared in accordance with ACI 211.3R [16] and PCA [14] recommendations; ACI 211.3R [16] provides a procedure for producing pervious concrete mixture proportions.

Table 1. A summary of composite mixtures developed in this study.

\begin{tabular}{|c|c|c|c|c|}
\hline Mix\# & Sample Label & PET (\%) & Soil (\%) & $\begin{array}{c}\text { Coarse } \\
\text { Aggregate (\%) }\end{array}$ \\
\hline 1 & P5 S5 & 5 & 5 & 90 \\
\hline 2 & P7.5 S5 & 7.5 & 5 & 87.5 \\
\hline 3 & P10 S5 & 10 & 5 & 85 \\
\hline 4 & P10 S0 & 10 & 0 & 90 \\
\hline 5 & P10 S10 & 10 & 10 & 80 \\
\hline
\end{tabular}

As indicated in Table 1, PPC samples were prepared by using different percentages of PET, coarse aggregates and soil. Mix \#1 through \#3 were prepared to study influence of PET content on indirect tensile strength and permeability. Additional mix \#3 through \#5 were 
prepared to study influence of soil content on indirect tensile strength and permeability of PPC. Specifically, PPC sample preparation consisted of the following steps:

Step 1 - The required amount of ingredients, namely, dry PET waste bottle flakes and soil were weighed according to the mix designs (Fig. 1a). The virgin coarse aggregates were washed a day prior to the sample preparation and oven dried at a temperature of $110 \pm 5^{\circ} \mathrm{C}$ for approximately 16 hours.

Step 2 - All ingredients were mixed in a stainless steel bowl and kept inside a preheated Ney Vulcan D-1750 oven at approximately $335 \pm 10^{\circ} \mathrm{C}$ for 15 minutes (Fig. 1b). After 15 minutes mixture was taken out from the oven and stirred using a steel spoon (Fig. 1c). The mixture was then put back into the oven for reheating and stirred again after another 10 minutes. This process was repeated three times until a homogenous mixture was obtained as shown in Fig. $1 d$.

Step 3 - Once homogenous mixture is achieved, molten mixture was taken out of oven and heated aggregates were added followed by mixing using a stainless steel spoon for 3 minutes (Fig. 1e). Then, mixture was heated again for another 15 minutes in the Ney Vulcan D-1750 oven at $335 \pm 10^{\circ} \mathrm{C}$ and stirred until homogenous mix is obtained as shown in Figs. $1 \mathrm{f}$ and $1 \mathrm{~g}$. Step 4 - Mixture obtained from Step 3 was poured in a pre-heated split cylindrical mold having a diameter of 4 inches and compacted to a height of 4 inches. Then, mixture was compacted in approximately three layers by using a steel rod in accordance with ASTM C 192 guidelines at room temperature.

Step 5 - Split mold containing compacted mixture was allowed to cool down at room temperature for 24 hours. After 24 hours sample was extracted from the mold and labeled using a tag. Figs. $1 \mathrm{~h}$ and $1 \mathrm{i}$ show photographic view of split mold containing compacted mixture and extracted sample, respectively.

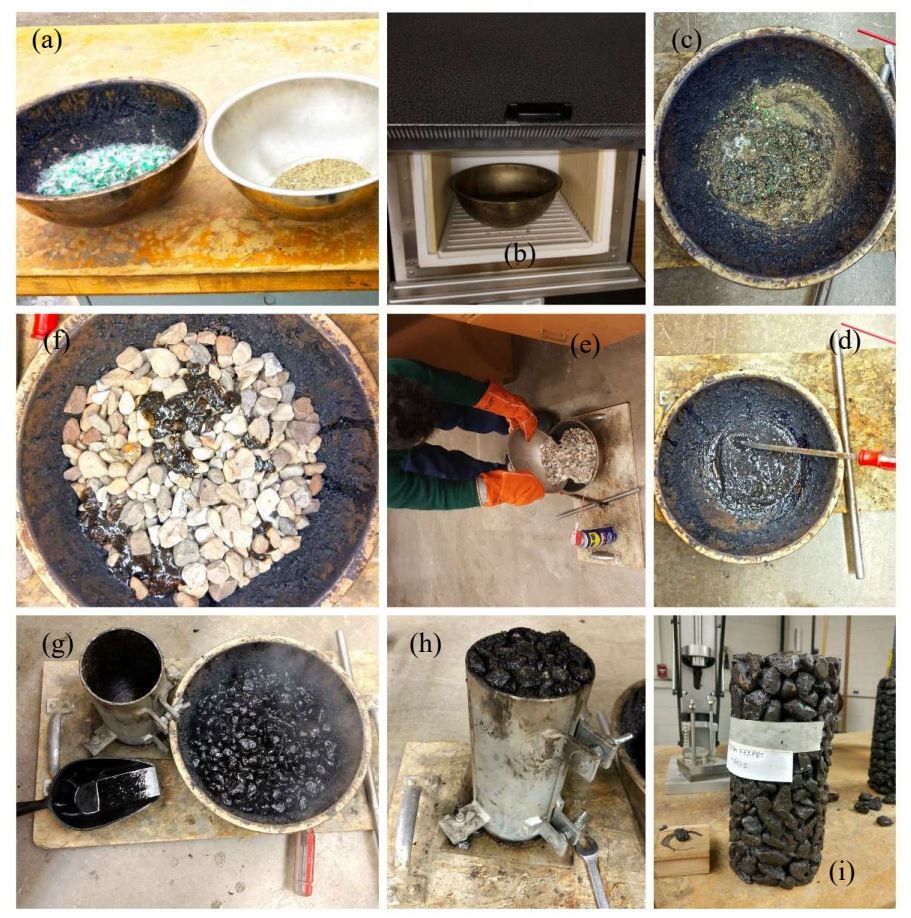

Fig. 3. PPC sample preparation steps (a-i).

\subsection{Laboratory tests}


Dry cylindrical samples of PPC were tested for indirect tensile strength and permeability. A brief description of each test is discussed in subsequent paragraphs.

\subsubsection{Indirect Tensile Strength}

Indirect tensile strength was conducted on replicates of PPC samples in accordance with the ASTM C 496M test method. The procedure consists of loading the specimen at a rate (vertical movement) of 0.5 inch per minute. Samples were tested in a universal testing machine using fixture designed for indirect tensile testing. Fig. 4 shows photographic view of sample before testing, test setup, and sample after testing. Tensile strength was calculated using the following equation:

$$
S_{t, n}=2 P_{f, n} /\left(\pi b_{n} D_{n}\right)
$$

where, $S_{t, n}=$ tensile strength of the specimen, $n, D_{n}=$ diameter of the specimen, $n, b_{n}=$ thickness of the specimen, $n$, and $P_{f, n}=$ maximum load observed for the specimen, $n$.

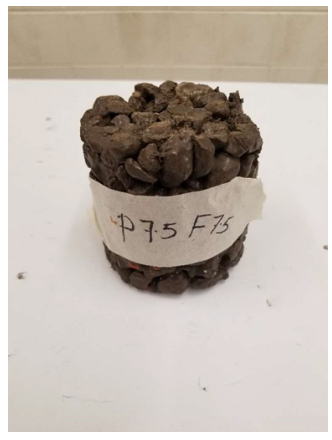

(a)

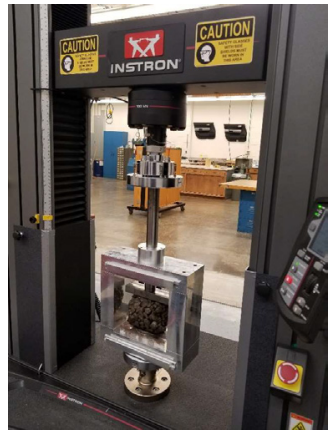

(b)

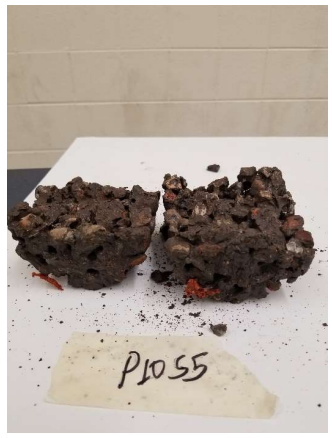

(c)

Fig. 4. Photographic view of (a) sample before testing, (b) indirect tensile strength testing setup, and (c) sample after testing.

\subsubsection{Permeability Test}

Permeability (or hydraulic conductivity) tests were conducted in accordance with ACI 522R [17] with few modifications. Specifically, specimens were tested for permeability using a constant-head permeameter test setup. A permeameter was designed and fabricated for testing PPC specimens (see photographic view in Fig. 5). With the valve closed, water was poured into the cylindrical mold until the water level remains steady at 7.25 inch above the opening valve, i.e., head. Time begins when the valve is opened. The test is complete and time is stopped when the water level in the graduated cylinder reaches $1000 \mathrm{ml}$. Each specimen was tested for at least three times and using the collected data, permeability was calculated. Additionally, at least two replicates were tested for each PPC mix to ensure repeatability and statistical significance. 


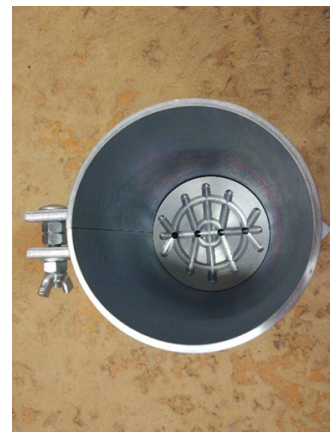

(a)

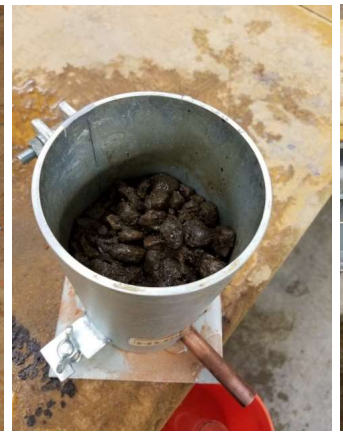

(b)

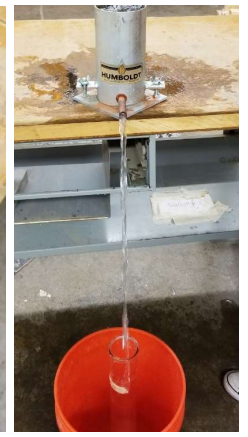

(c)

Fig. 5. Permeability setup (a) fabricated permeameter, (b) permeameter with PPC sample, and (c) PPC sample under testing.

\section{Analysis of data}

A summary of indirect tensile strength and permeability test results are presented in Table 2 . Aggregate and soil content were added and calculated as a ratio with respect to PET (AS/P). Additionally, aggregate to PET (A/P) ratio was calculated as shown in Table 2. Further, results are analyzed and discussed in sections below.

Table 2 A summary of indirect tensile strength and permeability values of PPC samples.

\begin{tabular}{|c|c|c|c|c|c|c|c|}
\hline $\begin{array}{c}\mathrm{M} \\
\mathrm{i}\end{array}$ & $\mathrm{PET}$ & $\begin{array}{c}\text { Soil } \\
\mathrm{x}\end{array}$ & $\begin{array}{c}\text { Coarse } \\
\text { Aggre } \\
\text { gate } \\
(\%)\end{array}$ & $\begin{array}{c}\text { (Aggregate+soil)/PET } \\
\text { ratio (AS/P) }\end{array}$ & $\begin{array}{c}\text { Aggregate/PET } \\
\text { ratio (A/P) }\end{array}$ & $\begin{array}{c}\text { Average } \\
\text { indirect } \\
\text { tensile } \\
\text { strength in } \\
\text { psi (kPa) }\end{array}$ & $\begin{array}{c}\text { Average } \\
\text { permeability } \\
\text { in ft/day } \\
(\mathrm{m} / \text { day })\end{array}$ \\
\hline 1 & 5 & 5 & 90 & 19 & 18 & $52(358)$ & $2226(679)$ \\
\hline 2 & 7.5 & 5 & 87.5 & 12.3 & 11.7 & $57(393)$ & $1210(369)$ \\
\hline 3 & 10 & 5 & 85 & 9 & 8.5 & $60(414)$ & $1163(355)$ \\
\hline 4 & 10 & 0 & 90 & 9 & 9 & $28(193)$ & $1242(379)$ \\
\hline 5 & 10 & 10 & 80 & 9 & 8 & $70(483)$ & $42(13)$ \\
\hline
\end{tabular}

\subsection{Indirect tensile strength}

The laboratory test results revealed that indirect tensile strength values increased with the increase in PET content. For example, increase in PET content from 5\% to 10\% (Mix\#1-3) increased indirect tensile strength value by approximately $15 \%$ (from 52 to $60 \mathrm{psi}$ ). Table 2 also indicates that strength values are also dependent on amount of soil in PET-soil glue which binds aggregates together. At a constant PET content of 10\% (Mix\#3-5), increase in soil content from 0 to $10 \%$ resulted in increase in indirect tensile strength values by approximately $150 \%$ (from 28 to 70 psi). Table 2 also indicates that same amount of PET was available for soil and aggregates in Mix\#3 through $5(\mathrm{AS} / \mathrm{P}=9)$. However, Mix\#5 provided highest strength indicating that using PET alone (Mix\#4) is not strong enough in binding aggregates together. A soil/PET ratio of one (Mix\#5) is optimum for providing maximum bonding strength between aggregates and PET-soil glue. It is also evident from Table 2 that soil/PET ratio was one for both Mix\#1 and Mix\#5. However, Mix\#5 provided higher strength as it had more PET available for aggregate and soil (lowest $\mathrm{AS} / \mathrm{P}=9$ ) as compared to Mix\#1 (highest AS/P = 19). 


\subsection{Permeability}

From Table 2 it is evident that the permeability values decreased with the decrease of A/P ratio. For example, the permeability values of specimens decreased from approximately 2226 $\mathrm{ft} /$ day (Mix\#1) to $1163 \mathrm{ft} /$ day (Mix\#3), as the A/P values decreased from 18 to 8.5 . This is due the fact that PET decreases air voids, thus reducing permeability values. Use of equal amount of soil and PET (soil/PET ratio $=1$ ) helped by making specimens porous but decreased indirect tensile strength. For example, both Mix\#1 and Mix\#4 had 10\% PET-soil glue but Mix\#1 had more open porous structure (2226 ft/day for Mix\#1 and $1242 \mathrm{ft} /$ day for Mix\#4) and reduced strength compared to Mix\#4. This could be attributed to $5 \%$ soil in Mix\#1 soil-PET glues compared to $0 \%$ soil in Mix\#1 soil-PET glue. A/P ratio of 8 results in $\mathrm{PPC}$ specimens with very low permeability (42 ft/day). Therefore, specimens with a A/P ratio of less than 8 were not prepared in this study. Additionally, both indirect tensile strength and permeability values of PPC mixtures were within the expected range found in the literature for pervious concrete and porous asphalt.

\section{Summary and Conclusions}

This study was undertaken to assess the mechanical and hydraulic properties of an innovative pervious PET composite, called as PPC, material prepared by using post-consumer plastic bottles. Using the mix designs, cylindrical samples of PPC were produced in a steel mold by compacting a mixture containing molten PET and heated aggregates and soil in accordance with proportions determined from mix design. Dry cylindrical samples of PPC were tested for indirect tensile strength and permeability. Indirect tensile strength was conducted in accordance with ASTM standard. However, permeability was conducted in a unique manner by designing and fabricating a new testing equipment.

Results showed that indirect tensile strength values increased with PET content. It was also found that using PET alone is not strong enough in binding aggregates and therefore, a soil/PET ratio of one was found optimum for providing maximum strength. Permeability values decreased with the decrease of $\mathrm{A} / \mathrm{P}$ ratio which in general indicates that lower PET and higher aggregate content is suitable for higher permeability. A soil/PET ratio of one was found to provide higher permeability but strength could compromise.

Findings from this study show that PPC could be used as a sustainable alternative for pervious pavements for low-strength construction such as driveways, sidewalks and parking lots. PPC is a unique alternative in that it addresses two environmental issues: reducing storm water runoff and diverting plastic waste from landfills and incinerators. As we continue our approach to sustainable and green construction materials, PPC is another step towards ecofriendly development.

Financial support for this study was provided through University Research Grant, College of Applied Science and Technology at Illinois State University. The material collection assistance provided by Prairie Material, Midwest Fiber Inc. and Lafarge North America is gratefully acknowledged. Also, plastic bottles donated by ISU recycling facility and students/faculty for conducting this research is gratefully acknowledged. 


\section{References}

1. Environmental Protection Agency (EPA) (2015). Advancing Sustainable Materials Management: 2013 Fact Sheet, Assessing Trends in Material Generation, Recycling and Disposal in the United States, June 2015.

2. National Association for PET Container Resources Member (NAPCOR) (2016). Postconsumer PET Container Recycling Activity in 2015, Report, Florence, KY.

3. Frigione, M. (2010). Recycling of PET Bottles as Fine Aggregate in Concrete, Waste Management, Vol. 30, pp. $1101-1106$.

4. www.myreplenish.com, accessed July 17, 2017

5. Mello, D., Pezzin, S. H. and Amico, S. C. (2009). The Effect of Post-Consumer PET Particles on the Performance of Flexible Polyurethane Foams, Polymer Testing, Vol. 28, pp. $702-708$.

6. Siddique, R., Khatib, J., and Kaur, I. (2008). Use of Recycled Plastic in Concrete: A Review, Waste Management, Vol. 28, pp. 1835 - 1852.

7. Sharma, R. and Bansal, P. P. (2016). Use of Different Forms of Waste Plastic in Concrete - A Review, Journal of Cleaner Production, Vol. 112, pp. 473 - 482.

8. Mobasher, B. and Li, C.Y. (1996). Effect of Interfacial Properties on the Crack Propagation in Cement Based Composites, Journal of Advanced Cement Based Materials, Vol. 4, pp. $93-105$.

9. Pezzi, L., De Luca, P., Vuono, E., Chiappetta, F., and Nasetro, A. (2006). Concrete Products with Waste's Plastic Material (Bottle, Glass, Plate). Journal of Materials Science Forum, Vols. 514 - 516, pp. 1753-0.

10. Tam, W.Y.V., Tam, C.M. and Wang, Y. (2007). Optimization on Proportion for Recycled Aggregate in Concrete Using Two-Stage Mixing Approach, Construction and Building Materials, Vol. 21, No. 10, pp. 1928 - 1939.

11. Fernando, P. T., Castro Gomes, J. P. and Said, J. (2008). Adhesion Characterization of Tungsten Mine Waste Geopolymeric Binder, Construction and Building Materials, Vol. 22, No. 3, pp. $154-161$.

12. Yao, Z., Zhang, X., Ge, Z., Jin, Z., Han, J., and Pan, X. (2015). Mix Proportion Design and Mechanical Properties of Recycled PET Concrete, ASTM Journal of Testing and Evaluation, Vol. 43, No. 2, pp. 1 - 9.

13. Hager, A. S. (2009). Sustainable Design of Pervious Concrete Pavements, PhD Dissertation, University of Colorado at Denver, Denver, CO.

14. Tennis, P., Leming, M., and Akers, D. (2007). Pervious Concrete Pavements, EB302.03, Portland Cement Association, Skokie, IL.

15. Huang, B., Wu, H. Shu, X. and Burdette, E. G. (2010). Laboratory Evaluation of Permeability and Strength of Polymer-modified Pervious Concrete. Construction and Building Materials, Vol. 24, pp. 818-823.

16. ACI 211.3R (2002). Guide for Selecting Proportions for No-Slump Concrete, American Concrete Institute, Farmington Hills, MI.

17. ACI 522R (2010). Report on Pervious Concrete, American Concrete Institute, Farmington Hills, MI. 